\title{
Study of the influence of cotton fiber indicators on yarn quality
}

\author{
Umida Yusupalieva $^{1 *}$, Saypila Matismailov ${ }^{1}$, and Alisher Yuldashev $^{1}$ \\ ${ }^{1}$ Department of Spinning Technology, Tashkent Institute of Textile and Light Industry, 100100 \\ Tashkent, Uzbekistan
}

\begin{abstract}
In order to determine the relationship between the fiber properties of the yarn quality in the article, experiments were conducted using a passive method of mathematical planning and a regression equation was obtained for each optimal parameter. Based on the experiments, it was found that a decrease in fiber micronaire, an increase in tensile strength, fiber length and uniformity, leads to an increase in the specific tensile strength of yarn, a decrease in the coefficient of variation in tensile strength and the number of breaks in the yarn.
\end{abstract}

\section{Introduction}

It is the task of the specialists of the textile industry to spin the quality of cotton fiber in accordance with world standards and produce finished export-oriented products. The priority of the quality of the yarn is the hardness index [1].

Because cotton is a natural fiber, its physical and mechanical properties can vary depending on different conditions, i.e., the type of seed, the area in which it is grown, and climatic conditions. This can affect the properties of the final products obtained from them. For successful mixing, it is always necessary to determine the types of constituent fibers and their respective proportions in the final mix [2].

As a multi-component blend of natural fibers with variable properties, there are a number of problems associated with determining the correct method of selecting fibers for spinning yarns with higher properties than cotton blends. It is known that the processes used in the production of yarn from short (short) fibers are very complex in nature. It is not enough to know the essence and characteristics of processes to successfully manage and optimize technological processes and increase equipment productivity, improve product quality [3].

For the study of complex processes, the solution of practical problems from computer technology as well as mathematically planned experiments is now being solved on a large scale. Accurate assessment of the physical nature of technological processes is very useful in solving the problem, eliminating the shortcomings of previous work, and is a priority in

\footnotetext{
*Corresponding author: umida.yusupalieva@mail.ru
} 
the modeling of the process [4]. The calculation of the properties of the yarn is calculated in accordance with the problem of optimizing the composition of the fiber mixture. In particular, it is important to use the fiber performance properties as a binding function or target function for the breaking phase of the yarn.

Accordingly, the following main directions of optimizing the composition of cotton fiber mixtures can be indicated [5-7]:

- $\quad$ to study the effect of cotton fiber properties on the relevant properties of yarn;

- to study the interaction of different fiber properties in the mix and to determine the generalized performance of the fiber mixture;

- Expansion of design issues at the expense of not only technological but also economic factors in the use of raw materials to obtain the optimal composition of the fiber mixture through the established criteria of optimization.

The alternative composition of the fiber mixture, the process of selecting components for working sorting, and the appropriate values of the factors influencing it should be provided to determine the optimal proportion of these components. With this in mind, an initial experimental methodology was presented to solve the subsequent research work.

\section{Materials and Methods}

The research was carried out on the technological equipment of the German company "TRUETZSCHLER" and "CHEX SAURER" installed in the training laboratory of the department of "Spinning Technology" of the Tashkent Institute of Textile and Light Industry:

1-Compact bale opener BO-C;

2-Compactor LVSA;

3- Blowing and mixing VE-963;

4 -Fiber cleaning and mixing machine CLENOMAT CVT-3;

5 -Aerodynamic dusting machine DX 803;

6- Carding machine DK 903;

7- Draw frame machine "HSR-1000";

8 -Pneumomechanical (OE) spinning machine BD-330.

In order to determine the relationship between the properties of cotton fiber and the properties of linear density 29 tex yarn in the method of OE spinning, experiments were conducted using the passive method of mathematical plan.

Passive research plays an important role in the study of processes performed in textile technologies, mainly in building the relationship between the performance of raw materials and the performance of yarn $[5,6]$.

The following properties of the raw material were accepted as undesirable factors.

-Micronaire index (Mic), $\mathrm{mg} / \mathrm{inch}$;

-Breaking strength of fiber, (Str) sN/tex;

-Upper Half-Mean Length (Len), mm;

-Uniformity index (UNF), \%.

\section{Results and Discussion}

These factors were selected on the basis of a priori data available in a number of theoretical studies, and the following model was used.

$$
y=b_{o}+\Sigma b_{i} x_{i}+\Sigma b_{i} x_{i}^{2}
$$


Equation (1) is useful in solving the problem of interpretation of passive studies and provides sufficient information about the linear $\left(x_{i}^{1}\right)$ nonlinear $\left(x_{i}^{2}\right)$ levels of factor influence $[8,9]$.

In constructing regression equations, the coded values of the factors were coded in the range $(-1)$ to $(+1)$ for each independent variable. When the minimum value of the independent variable is given as "-1", and the maximum value in the range " +1 ", the corresponding coded values of the factors of the natural level are obtained.

$$
x=\frac{\bar{x}_{\text {Ham }}-0,5\left(\bar{x}_{\min }+\bar{x}_{\max }\right)}{0,5\left(\bar{x}_{\min }-\bar{x}_{\max }\right)}
$$

A regression equation was obtained for each optimal parameter (Table 1).

Table 1. Spinning plan for linear density 29 tex (Ne 20) OE yarn production

\begin{tabular}{|c|c|c|c|c|c|c|c|c|c|}
\hline \multirow{2}{*}{ 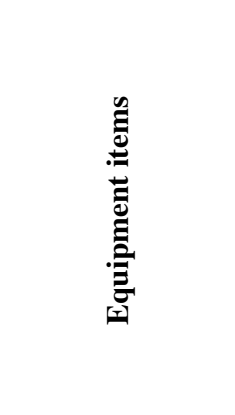 } & \multirow{2}{*}{ 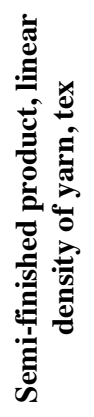 } & \multirow{2}{*}{ 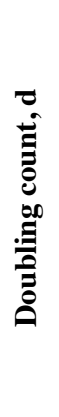 } & \multirow{2}{*}{ 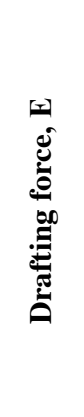 } & \multicolumn{2}{|c|}{ Twisting } & \multicolumn{2}{|c|}{ Speed } & \multirow{2}{*}{ 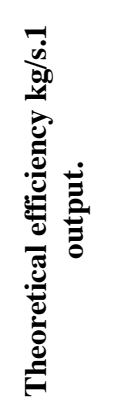 } & \multirow{2}{*}{ 氖 } \\
\hline & & & & $\alpha_{t}$ & \begin{tabular}{|c|}
$T$, \\
Twist per \\
meter
\end{tabular} & $\underset{\mathrm{m} / \mathrm{min}}{V}$ & $\begin{array}{c}n_{1} \\
\min ^{-1}\end{array}$ & & \\
\hline $\begin{array}{c}\text { Carding machine } \\
\text { DK-903 }\end{array}$ & 5848 & 1 & - & - & - & - & 64.3 & 75 & 0.94 \\
\hline $\begin{array}{l}\text { Draw frame 1-2- } \\
\text { transitions }\end{array}$ & 5000 & 6 & 7.2 & & & 800 & 6704.6 & 240 & 0.8 \\
\hline $\begin{array}{c}\text { OE spinning } \\
\text { machine BD-330 }\end{array}$ & 29 & 1 & 172.4 & 44.2 & 820 & 110.9 & 85000 & 0.1937 & 0.96 \\
\hline
\end{tabular}

Raw material quality indicators were determined on the instrument HVI 1000 [7], yarn quality indicators were determined on a modern measuring device PREMIER TESTING (India) in the manner specified in the standard (Technical normative document).

The PREMIER (India) testing equipment has a wide range of analysis capabilities based on the tables and graphs obtained from the quality of the product being tested. The results of the experiment were compared with the technical and regulatory document and international standards "USTER-STATISTICS 2018" [8].

The experiments were carried out in six variants of sorting, and in the study of each sort, the fiber quality indicators in the sorting were determined on the testing equipment "HVI" and the quality of yarn obtained in each variant. For each variant, cocoons were taken from TRUETZSCHLER draw frame machines and tested on PREMIER equipment to determine quality indicators. The test results are shown in Table 2.

As can be seen from the table, TRUETZSCHLER draw frame machines have a high linear density of the slivers, the presence of an automatic adjustment system, the flatness of the slivers in all variants is high (low unevenness) in sections of $1 \mathrm{~m}$.

The distribution of fiber mass across sections does not obey the normal law i.e. $\mathrm{CVm} / \mathrm{Um}=1.262-1.268$, while in normal distribution this ratio should be 1.25. 
The PREMIER instrument has the ability to detect asymmetry and excess along the distribution mass of fibers in the pile. As can be seen from the table, the asymmetry of the options is $0.4-0.9$. In option 5, it is 1.1 (which is close to the normal distribution law). According to the options, the excess rate is 2.6-2.8.

Table 2. Quality indicators of draw frame silver

\begin{tabular}{|c|c|c|c|c|c|c|}
\hline \multirow{2}{*}{ Items } & \multicolumn{7}{|c|}{ Variants } \\
\cline { 2 - 7 } & $\mathbf{1}$ & $\mathbf{2}$ & $\mathbf{3}$ & $\mathbf{4}$ & $\mathbf{5}$ & $\mathbf{6}$ \\
\hline Liner density, ktex & 4.92 & 4.96 & 4.88 & 4.96 & 4.92 & 4.94 \\
\hline Count, Nm & 0.203 & 0.202 & 0.205 & 0.202 & 0.203 & 0.202 \\
\hline CV 1m, \% & 0.82 & 0.89 & 0.85 & 0.94 & 0.9 & 0.77 \\
\hline $\begin{array}{c}\text { Unevenness: } \\
\text { - Um,\% }\end{array}$ & 4.16 & 4.57 & 4.24 & 4.52 & 4.10 & 3.75 \\
- CV,\% & 5.21 & 5.69 & 5.33 & 5.64 & 5.18 & 4.68 \\
\hline $\begin{array}{c}\text { An indication of the histogram of } \\
\text { asymmetry by mass }\end{array}$ & 0.2 & -0.9 & 0.4 & -0.6 & 1.1 & 0.8 \\
\hline $\begin{array}{c}\text { An indication of the excess histogram } \\
\text { by mass }\end{array}$ & 2.6 & 2.6 & 2.8 & 2.7 & 2.6 & 2.7 \\
\hline $\mathrm{C}_{\mathrm{m} / \mathrm{U}}$ & 1.252 & 1.261 & 1.257 & 1.248 & 1.269 & 1.248 \\
\hline
\end{tabular}

Table 3. Physical and mechanical properties of the yarn.

\begin{tabular}{|c|c|c|c|c|c|c|}
\hline \multirow{2}{*}{ Items } & \multicolumn{6}{|c|}{ Variants } \\
\hline & 1 & 2 & 3 & 4 & 5 & 6 \\
\hline Linear density o yanr, tex & 29.52 & 29.4 & 29.45 & 29.51 & 29.38 & 29.36 \\
\hline $\mathrm{CV} \mathrm{Nm}, \%$ & 2.2 & 2.3 & 2.3 & 2.4 & 2.2 & 2.1 \\
\hline Breaking force, $\mathrm{sN}$ & 345 & 312 & 321 & 316 & 335 & 355 \\
\hline $\begin{array}{l}\text { Tensile strength (RKM), } \\
\text { sN/teks }\end{array}$ & 11.7 & 10.6 & 10.9 & 10.7 & 11.4 & 12.1 \\
\hline CV rkm, $\%$ & 10.2 & 11.6 & 11.3 & 10.8 & 9.6 & 9.9 \\
\hline Elongation, \% & 5.3 & 4.7 & 5.0 & 4.9 & 5.1 & 5.6 \\
\hline $\mathrm{mm}$ & 2.65 & 2.35 & 2.5 & 2.15 & 2.55 & 2.8 \\
\hline Quality indicators & 1.147 & 0.914 & 0.965 & 0.99 & 1.187 & 1.222 \\
\hline Twisting, twist per meter & 846 & 843 & 852 & 848 & 850 & 856 \\
\hline Twist multiplier $\alpha_{\mathrm{T}}$ & 45.96 & 45.7 & 46.2 & 46.07 & 46.07 & 46.4 \\
\hline $\begin{array}{l}\text { The coefficient of utilization } \\
\text { of fiber strengths in yarn } \\
\text { strenghts, }\end{array}$ & 0.433 & 0.419 & 0.414 & 0.415 & 0.413 & 0.443 \\
\hline Breaking work, $\mathrm{N} \mathrm{cm}$ & 457.1 & 366.6 & $\begin{array}{c}401.2 \\
5\end{array}$ & 387.1 & 427.1 & 497 \\
\hline $\begin{array}{l}\text { The relative tensile strength } \\
\text { of } 1 \mathrm{~g} \text { of yarn, mdj }\end{array}$ & 30.97 & 24.94 & 27.25 & 26.24 & 29.07 & 33.88 \\
\hline $\begin{array}{l}\text { The number of fibers in the } \\
\text { cross section of the yarn }\end{array}$ & 163 & 149 & 153 & 156 & 162 & 169 \\
\hline $\begin{array}{c}\text { The number of breakage } \\
\text { yarn per } 1000 \text { cameras per } \\
\text { hour } \\
-1 \mathrm{~km}\end{array}$ & $\begin{array}{c}75 \\
11,1\end{array}$ & $\begin{array}{c}94 \\
13,9\end{array}$ & $\begin{array}{c}88 \\
13,2\end{array}$ & $\begin{array}{c}82 \\
12,2\end{array}$ & $\begin{array}{c}68 \\
10,1\end{array}$ & $\begin{array}{c}60 \\
9,01\end{array}$ \\
\hline
\end{tabular}

The magnitude of the excess corresponds to the recommendation of the yarn spun by the pneumomechanical method, which indicates the stability of the control parameters. Hence, 
it showed practically the same in all options. In 6 variants, the unevenness in $1 \mathrm{~m}$ sections is the smallest- $0.77 \%$, and in cross-sections- $3.75 \%$. It is known that the unevenness of the cocoon has a direct effect on the unevenness of the yarn produced [5].

From the coils supplied in the sequence of each variant, 29 tex yarns with a linear density were produced on the BD-330 pneumomechanical spinning machine. The quality of textiles, knitwear and other light industrial products is inextricably linked to the quality of the yarn spun [9]. The results of the average basic physical and mechanical properties of the yarn for the six variants are given in Table 3 .

As can be seen from Table 3, the yarn quality indicators in all variants meet the varietal requirements of the standard.

Fig. 1 shows the main physical and mechanical properties of the yarn according to the options in the form of histograms. It can be seen that the best performance in terms of specific tensile strength (12.1 sN/tex), unevenness (9.9\%) and elongation of the yarn was achieved in this sixth variant. The low performance of the yarn is seen as a second option.

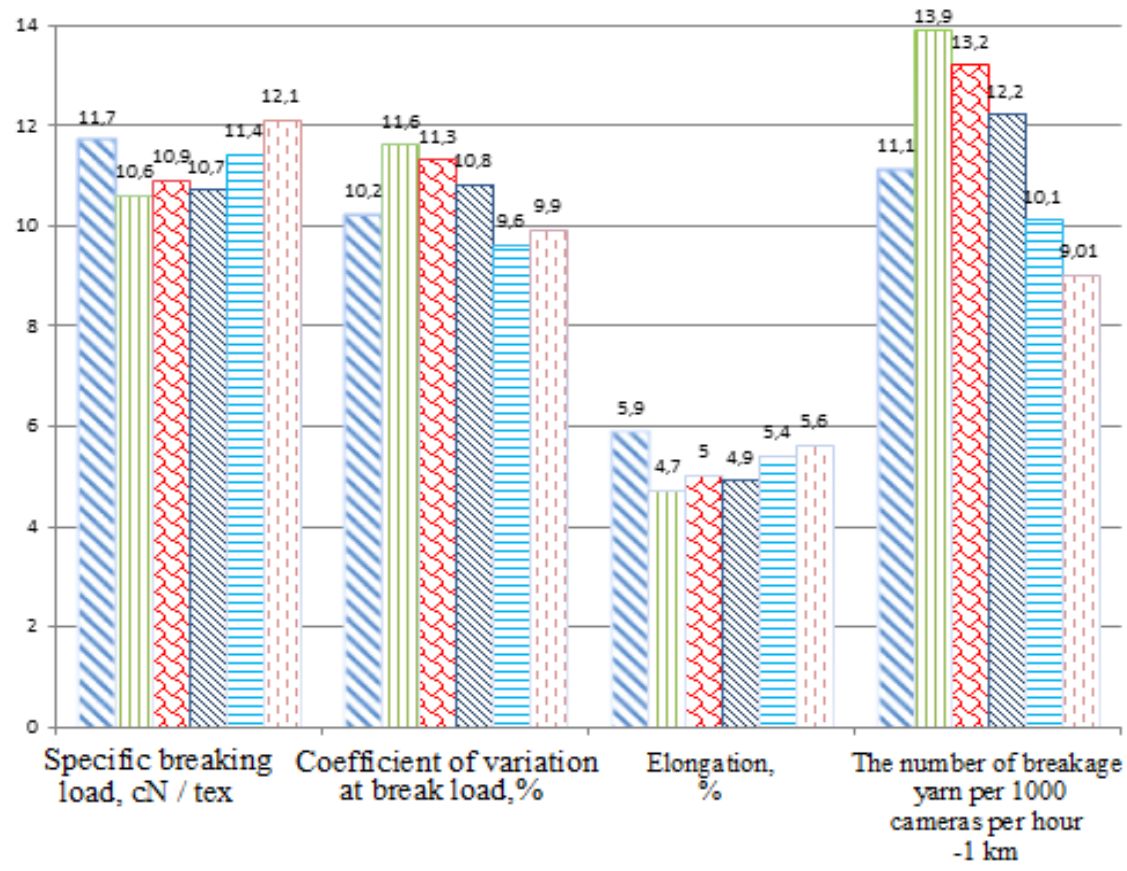

Fig.1. Basic physical and mechanical properties of the yarn

Table 4. Planning matrix and experimental results

\begin{tabular}{|c|c|c|c|c|c|c|c|}
\hline \multirow{2}{*}{$\#$} & \multicolumn{6}{|c|}{ Factors } & \multicolumn{3}{|c|}{ Alternative parameters } \\
\cline { 2 - 8 } & $\begin{array}{c}\boldsymbol{x}_{\mathbf{1}} \\
\text { Mic }\end{array}$ & $\begin{array}{c}\boldsymbol{x}_{\mathbf{2}} \\
\text { Len }\end{array}$ & $\begin{array}{c}\boldsymbol{x}_{\mathbf{3}} \\
\mathbf{S t r}\end{array}$ & $\begin{array}{c}\boldsymbol{x}_{\mathbf{4}} \\
\mathbf{U N F}\end{array}$ & $\begin{array}{c}\boldsymbol{y}_{\mathbf{1}} \\
\mathbf{s N} / \text { teks }\end{array}$ & $\begin{array}{c}\boldsymbol{y}_{\mathbf{2}} \\
\mathbf{C} \boldsymbol{\%}\end{array}$ & $\begin{array}{c}\boldsymbol{y}_{\mathbf{3}} \\
\text { Number of breakage } \\
\text { per 1000 cameras per } \\
\text { hour }\end{array}$ \\
\hline 1 & -0.333 & 1 & 0.478 & 0.236 & 11.7 & 10.2 & 75 \\
\hline 2 & 1 & -1 & -1 & -1 & 10.6 & 11.6 & 90 \\
\hline 3 & 0 & 0.098 & -0.13 & -0.418 & 10.9 & 11.3 & 88 \\
\hline 4 & 0.333 & -0.047 & -0.565 & -0.1273 & 10.7 & 10.8 & 82 \\
\hline 5 & -0.333 & -0.316 & 1 & 1 & 11.4 & 9.6 & 68 \\
\hline 6 & -1 & 0.472 & 0.739 & 0.782 & 12.1 & 9.9 & 60 \\
\hline
\end{tabular}


Regression equations were constructed based on the results of a passive experiment in estimating the degree of impact of cotton fiber on yarn performance. Table 4 was used to find the regression coefficients.

For the optimization parameters $\mathrm{y} 1, \mathrm{y} 2$, y 3 in the given equations $3 \div 5$, the coefficients of the regression equations were determined.

The significance of the coefficients of the equation was determined as the Student's criterion [7-9]. The tabular value of the criterion is $t=4.3 \mathrm{f}(3-1)=2$ for the degree of freedom, the value of the criterion $t$ is 0.05 ).

If so, the coefficient is significant.

After subtracting the insignificant coefficients, the regression equations look like this:

- Tensile strength of the yarn, sN/tex

$$
y_{1}=11,23-0,47 x_{1}+0,61 x_{3}+0,53 x_{4}
$$

- CV of a yarn on breaking force, $\%$

$$
y_{2}=10,566+0,204 x_{1}-0,139 x_{2}+0,43 x_{3}+0,341 x_{4}
$$

- Number of breakages of yarn per 1 hour for 1000 cameras

$$
y_{3}=77,83+3,84 x_{1}-2,05 x_{2}-2,4 x_{3}-4,49 x_{4}
$$

The adequacy of the obtained equations (4.14-4.16) was checked using the Fisher criterion.

$$
F=\frac{S_{a g_{i}}^{2}}{S_{y_{i}}^{2}}
$$

The calculated value of the adequacy variance alternative parameter is a measure of the deviation between $\mathrm{Y}_{\text {calc }}$ and the practical value $\mathrm{Y}_{\text {appl }}$. If $\mathrm{F}_{\text {calc }}<\mathrm{F}_{\text {tab }}$ is 0.05 , the model is considered adequate.

\section{Conclusions}

1. As a result of increasing the strengths and decreased unevenness of the yarn, the stability of the spinning process has improved and the number of breakages yarn in spinning machines has decreased. The number of breaks in the $1 \mathrm{~km}$ yarn was 9 in 6 options, a decrease of $35.3 \%$ compared to 2 options, and the number of breaks in the other options was also low.

2. By making sure that equations (3-5) are adequate, the following conclusion can be drawn. In OE yarn spinning, the length of the fiber, the fineness of the fiber, the tensile strength, and one plane can be put in the fourth place.

3. A decrease in the level of micronaire value to an increase in tensile strength, fiber length and uniformity, an increase in the tensile strength of the yarn, a decrease in the coefficient of variation in the tensile strength and the number of breaks in the yarn.

Thus, using the passive experimental method, it was proved that it is possible to determine the optimization parameters using regression relationships between the quality indicators of the mixture and the properties of the yarns. 


\section{References}

1. K. Jumaniyazov, K. Gafurov, F. Raxmatullinov, Problems of textile 2, 11 (2012)

2. U. N. Yusupalieva, F. F. Raxmatullinov, Uzbek journal of textile 2(3), 10 (2021)

3. Y. El Mogahzy, Y. Gowayed, Textile Research Journal 65(1), 32-40 (1995)

4. A. Ghosh, A. Majumdar, S. Das, Fibers and Polymers 13(6), 809-813 (2012)

5. Sh. Korabaev, S. Matismailov, A. Yuldashev, D. Atanbaev, Solid State Technology 63(6), 15 (2020)

6. F. Raxmatullinov, S. Matismailov, Tekhnologiya tekstilnoy promishlennosti 6(384), 121-125 (2013)

7. L. Amzaev, Altering technological processes, 415 (TTYeSI Press, Tashkent, 2008)

8. U. Meliboev, Principles of textile processing models, 224 ("Adabiyot uchqunlari” Press, Namangan, 2020)

9. A. Yuldashev, S. Matismailov, Sh. Korabayev, Sh. Aripova, Q. Matmuratova, Turkish Journal of Computer and Mathematics Education 12(5), 1943-1949 (2021) 